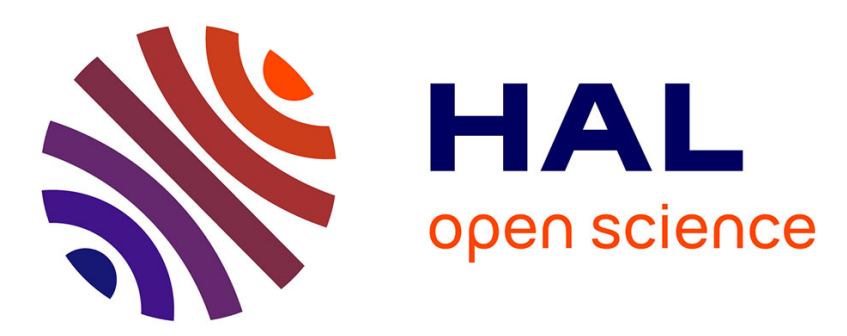

\title{
The influence of the solvent in fast neutron/gamma discrimination
}

\author{
M. Hamel, A.M. Frelin-Labalme, S. Normand
}

\section{To cite this version:}

M. Hamel, A.M. Frelin-Labalme, S. Normand. The influence of the solvent in fast neutron/gamma discrimination. EPL - Europhysics Letters, 2014, 106, pp.52001. 10.1209/0295-5075/106/52001 . in2p3-01009127

\section{HAL Id: in2p3-01009127 https://hal.in2p3.fr/in2p3-01009127}

Submitted on 3 May 2019

HAL is a multi-disciplinary open access archive for the deposit and dissemination of scientific research documents, whether they are published or not. The documents may come from teaching and research institutions in France or abroad, or from public or private research centers.
L'archive ouverte pluridisciplinaire HAL, est destinée au dépôt et à la diffusion de documents scientifiques de niveau recherche, publiés ou non, émanant des établissements d'enseignement et de recherche français ou étrangers, des laboratoires publics ou privés. 


\title{
THE INFLUENCE OF THE SOLVENT IN FAST NEUTRON / GAMMA DISCRIMINATION
}

\author{
M. HAMEL ${ }^{1(a)}$, A.-M. Frelin-LABALME ${ }^{2}$ and S. Normand ${ }^{1}$ \\ ${ }^{1}$ CEA, LIST, Laboratoire Capteurs et Architectures Électroniques, F-91191 Gif-sur-Yvette Cedex, France \\ ${ }^{2}$ GANIL, CEA/DSM-CNRS/IN2P3, Bd H. Becquerel, Caen, France
}

received and accepted dates provided by the publisher

other relevant dates provided by the publisher

PACS 29.40. MC - Scintillation detectors

PACS 33.50.Dq - Fluorescence of molecules

\begin{abstract}
The biphenyl / POPOP couple is known for its scintillation properties, but we describe in this note its use for the discrimination between fast neutrons and gamma rays. More particularly, the influence of the matrix involved in this process is of interest, and for the first time pulse shape discrimination has been observed in non-common solvents such as heptane or ethanol. The discrimination efficiency of our systems is described in terms of factor of merit, angle between neutron and gamma lobes and scintillation performances.
\end{abstract}

Introduction. - Due to the worldwide shortage of ${ }^{3} \mathrm{He}$, alternative, efficient neutron detectors would be of great value. Among them, liquid scintillators can represent a good choice in terms of detection efficiency, neutron / gamma discrimination and overall cost. Unfortunately, their main drawbacks are related to their toxicity, their loss of performances while in contact with oxygen and their possibility to leak. Major users have therefore turned their attention to "heavy" organic scintillators, such as alkylnaphthalenes, phenylxylylethane (PXE), or linear alkyl benzene (LAB), and even water-based liquid scintillators [1]. To this aim, new environmentally- and operator-friendly liquid scintillators would be appreciated. In parallel to our preliminary work on the use of specially designed fluorophores suitable for Pulse Shape Discrimination (PSD) in liquid scintillators [2], we wish to describe in this note that a mixture of biphenyl and POPOP (1,4-bis-(5-phenyl-2oxazolyl)benzene) could represent a non-toxic, low-cost bivalent mixture used for scintillation counting as well as PSD between fast neutrons and gamma rays. Although not commonly used, biphenyl would present all the characteristics suitable for scintillation purpose: absorption in the $300 \mathrm{~nm}$ region, emission in the UV around $360 \mathrm{~nm}$ and high solubility in non-polar media. So this compound could theoretically be engaged in fast neutron/gamma discrimination.

In this study, this mixture has been more particularly tested in totally uncommon scintillating solvents such as ethanol where, despite a modest light output, PSD was observable. To the best of our knowledge, it is the first time that non-aromatic solvents are used to this purpose.
Materials and methods. - Four biphenyl / POPOP solutions were evaluated in terms of decay times, relative light output and neutron-gamma discrimination. A mixture of $p$ terphenyl and POPOP in toluene was prepared as reference, which already proved to be a good neutron detector with an excellent light yield [2]. Two commercially available liquid scintillators (NE-213 and Ultima Gold AB) were also evaluated for better comparison.

All experiments were performed with $38 \times 10 \times 10 \mathrm{~mm}^{3}$ quartz tank containing the liquid scintillator to be analysed. This sample was optically coupled with optical grease to a Photonis XP2020 photomultiplier tube. This PMT is known to present a maximum of sensitivity at $420 \mathrm{~nm}$ and the following time response: rise time $1.7 \mathrm{~ns}$ and FWHM $2.7 \mathrm{~ns}$. The

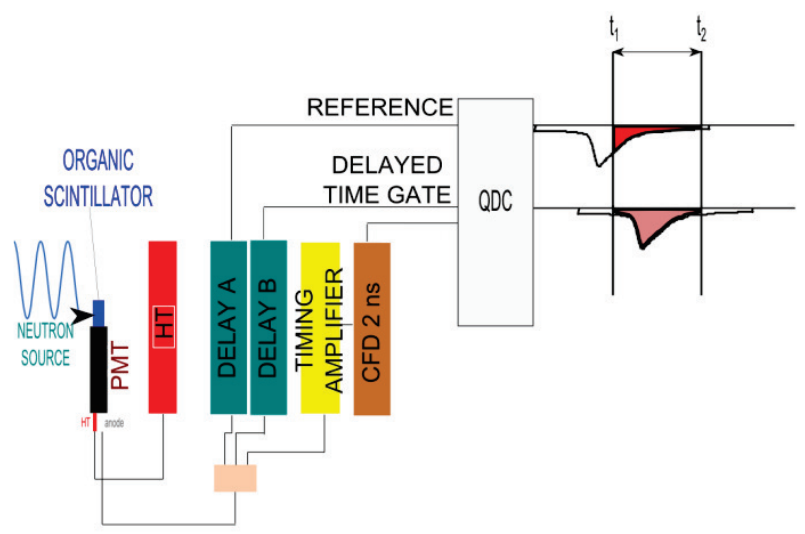

Fig. 1: Experimental set-up of the charge integration comparison method for $\mathrm{n} / \gamma$ discrimination.

\footnotetext{
${ }^{(a)}$ E-mail: matthieu.hamelecea.fr (please do not send commercial emails)
} 


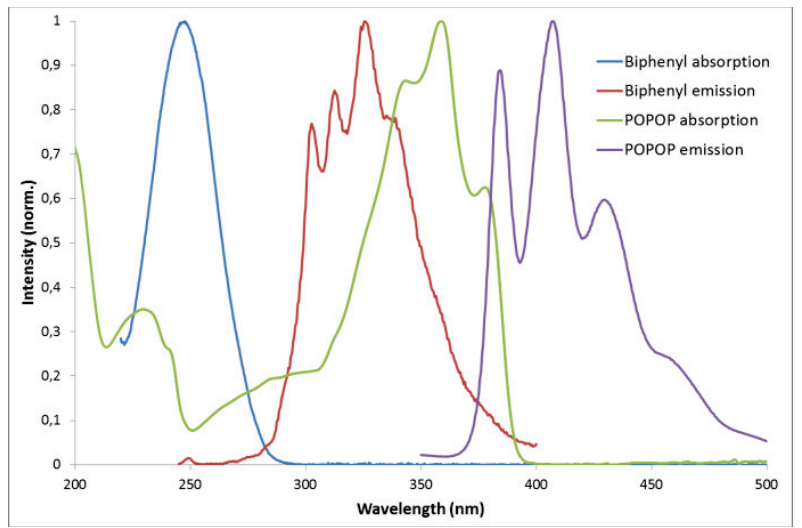

Fig. 2: Absorption and emission of biphenyl and POPOP (theoretical data).

applied high voltage was $-2000 \mathrm{~V}$ for all experiments.

Decay times of the different scintillator solutions were evaluated in the presence of a ${ }^{60} \mathrm{Co}$ source, from the record of several thousand waveforms with a LeCroy WP7300A oscilloscope ( $3 \mathrm{GHz}, 20 \mathrm{Gs} / \mathrm{s})$. Relative light outputs were estimated from the average pulse height of these several thousand pulses.

Emission spectra were recorded with a Horiba Jobin Yvon Fluoromax 4P spectrofluorometer with the abovementioned quartz tank.

PSD performances of each liquid scintillator were observed under a $74 \mathrm{MBq}{ }^{252} \mathrm{Cf} \mathrm{n} / \gamma$ source located $5 \mathrm{~cm}$ away from the sample (ca. 10,000 n / s). Each solution was fully degassed with Argon for several minutes prior to experiment. Charge comparison method was chosen for discrimination

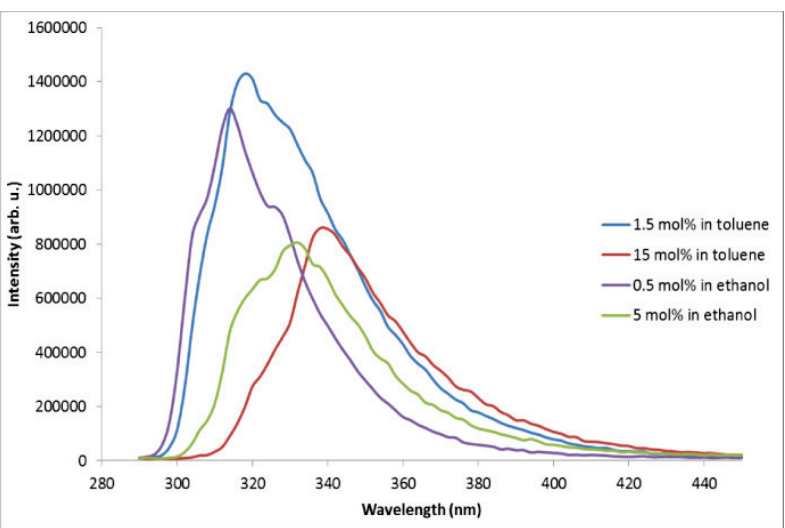

Fig. 3: Emission spectra of concentrated and diluted biphenyl in toluene and ethanol $\left(\lambda_{\mathrm{ex}}=270 \mathrm{~nm}\right.$, same slits for all experiments).

experiments [3] and the experimental set-up given in Fig. 1 provided the biparametric spectrum of $n / \gamma$ discrimination. These spectra permitted the evaluation of discrimination performances in terms of Figure of Merit and theta angle (see Table 1).

Results and discussion. - Biphenyl displays a moderate fluorescence quantum yield (ca. 0.2 in benzene at room temperature) but due to the strong overlap between its emission and the absorption of POPOP (Fig. 2), this system is well-designed for commonly used photomultipliers. Biphenyl is also known to produce easily triplet states and consequently delayed fluorescence [4].

Table 1. Scintillating and discriminating properties of the biphenyl / POPOP couple in various solvents and comparison with efficient and commercial scintillators.

\begin{tabular}{llllll}
\hline \multirow{2}{*}{ Entry } & Liquid Scintillator $^{(\mathrm{a})}$ & $\begin{array}{l}\text { Light } \\
(\%)^{(\mathrm{b})}\end{array}$ & $\begin{array}{l}\text { Decay time } \\
80 / 20(\mathrm{~ns})\end{array}$ & Figure Of Merit $^{(\mathrm{c})}$ & $\theta^{(\mathrm{d})}$ \\
\hline 1 & $p^{\text {-terphenyl/POPOP }(4 / 0.1 \mathrm{~g} / \mathrm{L}) \text { in toluene }}$ & 100 & 7.28 & $0.6-1.9(40-280)$ & 5.0 \\
2 & NE-213 & 101 & 9.02 & $0.8-1.8(35-200)$ & 7.8 \\
3 & Ultima Gold AB $_{4}$ & 100 & 9.85 & $0.7-1.3(40-135)$ & 7.0 \\
4 & Biphenyl/POPOP in toluene $_{5}$ & 101 & 13.04 & $0.5-2.0(30-200)$ & 8.3 \\
6 & Biphenyl/POPOP in heptane $^{(\mathrm{e})}$ & 12 & 17.43 & $0.3-0.5(40-100)$ & 4.0 \\
7 & Biphenyl/POPOP in xylene $(\mathrm{s})^{\text {Biphenyl/POPOP in ethanol }}{ }^{(\mathrm{f})}$ & 69 & 11.23 & $0.6-2.0(20-200)$ & 9.2 \\
\hline
\end{tabular}

(a) $15 \mathrm{~mol} \%$ of biphenyl and $0.1 \mathrm{~mol} \%$ of POPOP in the corresponding solvent, unless otherwise stated.

(b) Relative light output normalized to 100 for the scintillator reference, entry 1 .

(c) Calculated from the equation: FOM $=D_{\gamma-n} / L_{\gamma F W H M}+L_{n F W H M}$, where $D_{\gamma-n}$ is the separation between the gamma and the

neutrons peaks in the biparametric spectra and $L$ is the full width at half maximum for each peak [5]. Worst and best FOMs are given in terms of the lowest and largest charge signals, and their range in $\mathrm{pC}$ is given in parentheses.

\footnotetext{
(d) Angle in degree formed between neutron and gamma lobes.

(e) Saturated solution in biphenyl. [c] $]_{\text {sat }} \approx 9 \mathrm{~mol} \%$.

(f) Concentration in biphenyl [c] $=5$ mol\%. $99.6 \%$ ethanol.
} 


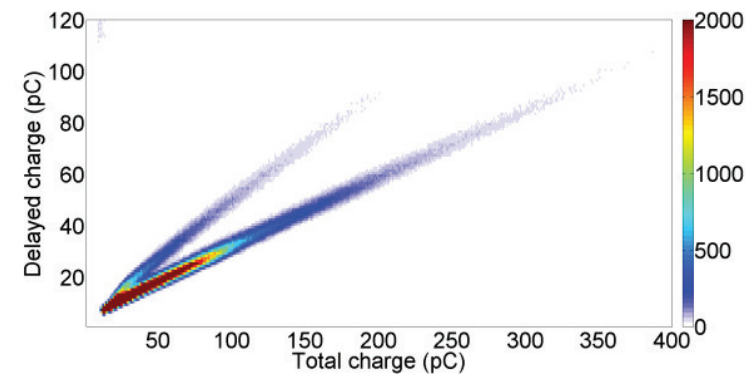

Fig. 4: Biparametric spectrum of $n / \gamma$ discrimination of a biphenyl / POPOP solution in toluene (entry 4 from Table 1).

Comparative results of the different scintillating solutions are presented in Table 1. The $p$-terphenyl / POPOP couple was chosen to be our absolute liquid scintillator reference and different commercial liquid scintillators were preliminary compared with already published results: NE-213 and Ultima Gold AB.

We then investigated the mixture of biphenyl and POPOP (15 and $0.1 \mathrm{~mol} \%$, respectively, unless otherwise stated in Table 1) in various solvents.

The relative light outputs of commercial scintillators (entries $2 \& 3$ from Table 1) have been shown to be similar to the lab-made reference $p$-terphenyl / POPOP mixture in toluene. Biphenyl / POPOP in toluene solution also displayed similar results and xylenes solution showed a satisfying light output of $69 \%$. Non-polar solvents (heptane and ethanol) did not result in many photons, with a relative light output of only $12 \%$ compared to $p$-terphenyl / POPOP in toluene.

Decay times recorded from irradiation of the liquid scintillator with a ${ }^{60} \mathrm{Co}$ source were found to be larger than with standard liquid scintillators, with decay times longer than $10 \mathrm{~ns}$, possibly because of the creation of biphenyl dimers or excimers in our concentrated solutions. This has been confirmed in separate experiments (Fig. 3), where emission spectra of concentrated and diluted toluene and ethanolic solutions of biphenyl have been recorded. As expected and confirmed in [4], the emission spectra are shifted to upper wavelengths when concentrated solutions are studied, both for toluene and ethanol, with emission maxima ranging from 314 $-318 \mathrm{~nm}$ to $332-338 \mathrm{~nm}$, revealing higher concentrations of excimers. These are known to show longer decay times than corresponding monomers [6]. It is noteworthy that commercial scintillators' decay times recorded with our setup experiment were also longer (3.2 ns for the short component of decay time for BC-501A, which is a known equivalent of

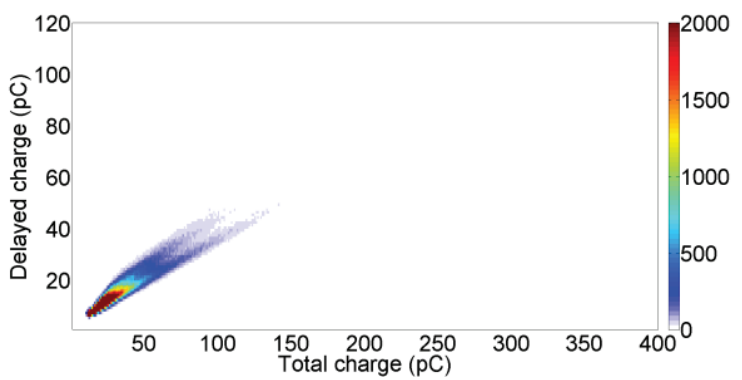

Fig. 5: Biparametric spectrum of $n / \gamma$ discrimination of a biphenyl / POPOP solution in heptane (entry 5 from Table 1).

\section{NE-213 [7]).}

The $\mathbf{n} / \boldsymbol{\gamma}$ discrimination study with our setup conditions displayed the Figure of Merit and theta angle consistent with literature for NE-213 [8] and Ultima Gold AB, with PSD capabilities slightly lower than reported for the latter sample. Concerning lab-made liquid scintillators, the study has shown very surprising and interesting results as very simple systems in toluene or xylene(s) could be as efficient as commercial scintillators both for the FOM (Figure of Merit) and for the angle measured between the neutron and the gamma lobes. More interestingly and despite slightly lower performances, discrimination was also achieved in non-aromatic solvents, such as ethanol and heptane, which are not common solvents for scintillation counting.

The biparametric spectrum obtained for toluene (Fig. 4) and the corresponding evolution of the FOM as a function of the total charge (Fig. 6) clearly show that the biphenyl / POPOP couple in aromatic solvents gives excellent results in terms of PSD, with values close or higher than those of commercial scintillators specially designed to this aim. As one

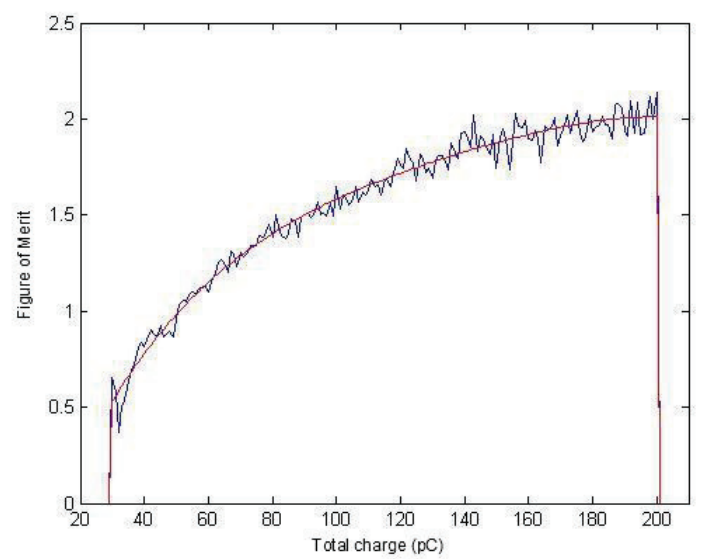

Fig. 6: Evolution of the Figure Of Merit value with the total charge for the biphenyl / POPOP couple in toluene (15 mol\% and $0.1 \mathrm{~mol} \%$, respectively).

can see, a value of FOM $=1$ is reached for a total charge of ca. 50 pC. As summarized in Table 1, comparable results were obtained with xylene.

The biparametric spectrum obtained for heptane (Fig. 5) clearly shows separated neutron and gamma lobes (similar results with ethanol), the highest $\theta$ angle even being observed for ethanol-based liquid scintillator.

Despite lower FOM values explained by the poor relative light output, and consequently higher statistical uncertainties, this is the first example of discrimination between fast neutrons and gamma rays in non-aromatic solvents, such as heptane and ethanol. How can it work? Regarding the recent advances in $n / \gamma$ PSD in plastic scintillators [9] (which were for a long time assumed to be unable to perform a good discrimination), an extremely important concentration of primary fluorophore is the key solution. Indeed, ethanol and 
heptane cannot perform Förster energy transfer. Thus, the only possibility for both of them to scintillate is to have a primary fluorophore / primary solute, or in other words a primary fluorophore able to act as a chromophore and an aromatic solvent, as was described by Brooks et al. [10]. To discriminate, triplet states mandatory for performing $n / \gamma$ PSD are available in sufficient quantity in our system. Biphenyl seems one of the best candidates to this purpose.

Conclusion. - This technical note deals with the study of the matrix influence in $n / \gamma$ discrimination. For the first time, PSD between fast neutrons and gamma is described in unusual scintillating solvents such as ethanol and heptane. Ethanol could be of great value for the analysis of neutronemitting radionuclides dissolved in water, but the low light output somehow limits the PSD capabilities. Future experiments will be conducted on binary mixtures of solvents. Scale-up of the size of the cell would also be of great value, according to [5].

This work was carried out with the support of the French governmental agency "Agence Nationale de la Recherche" and NEUTROMANIA program for the grant to M.H.

\section{REFERENCES}

[1] Yeh M., Hans S., Beriguete W., Rosero R., Hu L., HahN R. L., Diwan M. V., JafFe D. E., KetTEll S. H. and LitTenberG L., Nucl. Instr. Methods A, 660 (2011) 51 .

[2] (a) Hamel M., Normand S. and Simic V., PCT Patent Application, WO2009095376, 2009; (b) HAMEL M., Frelin-Labalme A.-M., Simic V. and NoRMAND S., Nucl. Instr. Methods A, 602 (2009) 425; (c) HAMEL M., NoRMAND S., FRELIN A.-M. and SIMIC V., In LSC 2008, Advances in Liquid Scintillation Spectrometry 2008, p 13.

[3] (a) BELL Z. W., Nucl. Instr. Methods, 188 (1981) 105; (b) For a detailed representation of the technology and physical procedure, refer to: NORMAND S., MOUANDA B., HAAN S. and LOUVEL M., Nucl. Instr. Methods A, 484 (2002) 342.

[4] Loewenthal E. and Weinreb A., J. Chem. Phys., 44 (1966) 2534.

[5] Moszyński M., Costa G. J., Guillaume G., HeUSCH B., HuCK A. and Mouatassim S., Nucl. Instr. Methods A, 350 (1994) 226.

[6] Valeur, B. Molecular Fluorescence. PrinciPLES AND APPLICATIONS; WILEY-VCH: WEINHEIM, 2002.

[7] http://www.crystals.saintgobain.com/uploadedFiles/SG-

Crys-
tals/Documents/SGC\%20BC501_501A_519\%20Data $\%$ 20Sheet.pdf

[8] Bayat E., Divani-Vais N., Firoozabadi M. M. and GHal-EH, N. Radiat. Chem. Phys., 81 (2012) 217. [9] (a) BLANC P., HAMEL M., DEHÉ-PITTANCE C., ROCHA L., PANSU R. B., NORMAND S. Nucl. Instr. Methods A, 750 (2014), 750, 1; (b) ZAITSEVA N., CARman L., Glenn A., Hamel S., PAYne S. A., Rupert B. L., PCT Patent Application, WO2012142365, 2012.

[10] Brooks F. D., Pringle R. W. and Funt B. L. IRE Trans. Nucl. Sci., NS-7 (1960) 35. 